\title{
Comparison of First- and Second-Generation Drug-Eluting Stents in Patients with Acute Myocardial Infarction and Prediabetes Based on the Hemoglobin A1c Level
}

\author{
Yong Hoon Kim (D, ${ }^{1}$ Ae-Young Her, ${ }^{1}$ Myung Ho Jeong, ${ }^{2}$ Byeong-Keuk Kim (D, ${ }^{3}$ \\ Sung-Jin Hong, ${ }^{3}$ Seunghwan Kim, ${ }^{4}$ Chul-Min Ahn, ${ }^{3}$ Jung-Sun Kim $\mathbb{D},{ }^{3}$ Young-Guk Ko $\mathbb{D}^{3},{ }^{3}$ \\ Donghoon Choi $\mathbb{D}^{3},{ }^{3}$ Myeong-Ki Hong $\mathbb{D}^{3},{ }^{3}$ and Yangsoo Jang ${ }^{3}$ \\ ${ }^{1}$ Division of Cardiology, Department of Internal Medicine, Kangwon National University School of Medicine, \\ Chuncheon, Republic of Korea \\ ${ }^{2}$ Department of Cardiology, Chonnam National University Hospital, Gwangju, Republic of Korea \\ ${ }^{3}$ Division of Cardiology, Severance Cardiovascular Hospital, Yonsei University College of Medicine, Seuol, Republic of Korea \\ ${ }^{4}$ Division of Cardiology, Inje University College of Medicine, Haeundae Paik Hospital, Busan, Republic of Korea
}

Correspondence should be addressed to Yong Hoon Kim; yhkim02@kangwon.ac.kr

Received 19 December 2019; Revised 27 February 2020; Accepted 20 June 2020; Published 18 July 2020

Academic Editor: Andrea Rubboli

Copyright (c) 2020 Yong Hoon Kim et al. This is an open access article distributed under the Creative Commons Attribution License, which permits unrestricted use, distribution, and reproduction in any medium, provided the original work is properly cited.

\begin{abstract}
Objective. To compare major clinical outcomes after successful percutaneous coronary intervention (PCI) with first-generation $(1 \mathrm{G})$ drug-eluting stents (DES) and second-generation (2G) DES in patients with acute myocardial infarction (AMI) and prediabetes. Background. Patients with prediabetes are associated with an increased incidence of coronary artery disease. The relative superiority of 1G- and 2G-DES in these patients is not well established. Methods. A total of 4997 patients with AMI and prediabetes were divided into two groups: the 1D-DES group $(n=726)$ and the $2 \mathrm{G}$-DES group $(n=4271)$. The primary outcomes were the patient-oriented composite outcomes (POCOs) defined as all-cause death, recurrent myocardial infarction (Re-MI), and any disease revascularization at 2-year follow-up. The secondary outcome was probable or definite stent thrombosis (ST). Results. After propensity score-matching (PSM) analysis, two PSM groups (698 pairs, $n=1396$, C-statistics $=0.725)$ were generated. The cumulative incidence rates of POCOs (hazard ratio (HR): 1.467; 95\% confidence interval (CI): 1.068-2.015; $p=0.018$ ), any disease revascularization (HR: 2.259; 95\% CI: $1.397-3.654 ; p=0.001$ ), and ST (HR: 4.361; 95\% CI: $1.243-15.30 ; p=0.021$ ) in the $1 \mathrm{G}-\mathrm{DES}$ group were significantly higher than those in the 2G-DES group. However, the cumulative incidence rates of all-cause death, cardiac death, and Re-MI were similar between the two groups. Conclusions. In patients with AMI and prediabetes, 2G-DES implantation was more efficacious than 1G-DES implantation over a 2-year follow-up period. However, further studies are needed to confirm these results.
\end{abstract}

\section{Introduction}

In the fibrinolytic era, hyperglycemia, rather than normoglycemia, was a major independent prognostic factor of adverse clinical outcomes in patients with acute myocardial infarction (AMI) $[1,2]$. Similarly, in the drug-eluting stent (DES) era, hyperglycemia is an independent predictor of early and late mortality in patients with ST-segment elevation myocardial infarction (STEMI) regardless of the presence or absence of known diabetes [3, 4]. The exact mechanisms by which hyperglycemia is associated with adverse major clinical outcomes in AMI have not been fully elucidated yet. With regard to diabetes mellitus (DM), many studies have shown its association with higher long-term risk of death, myocardial infarction (MI), and repeat revascularization in patients undergoing percutaneous coronary 
intervention (PCI) [5-7]. Patients with prediabetes are at an increased risk of cardiovascular disease (CVD), and prediabetes is associated with an increased incidence of coronary artery disease (CAD) $[8,9]$. Even though the relative superiority between the first-generation $(1 \mathrm{G})$ and secondgeneration $(2 \mathrm{G})$ DESs in patients with AMI is controversial [10-12], most previous studies were not performed under the circumstance of prediabetes. Therefore, the comparative long-term clinical outcomes between the two DES generations were limited. Hence, we investigated and compared the major clinical outcomes after successful PCI with 1G-DES and 2G-DES in patients with AMI and prediabetes over a 2year follow-up period.

\section{Methods}

2.1. Study Population. This study was a nonrandomized, multicenter, observational, and retrospective cohort study. A total of 45863 patients from the Korea AMI Registry (KAMIR) who had AMI and underwent successful stent implantation between November 2005 and June 2015 were evaluated. KAMIR is the first nationwide and multicenter registry that included $>50$ community and teaching hospitals in South Korea since November 2005 [13]. Eligible patients were aged $\geq 18$ years at the time of hospital admission. Among the patients, those with incomplete laboratory results, including unidentified blood hemoglobin ( $\mathrm{Hb}$ ) A1c and blood glucose test results $(n=27737,60.5 \%)$, those who were lost to follow-up $(n=3275,7.1 \%)$, those who received a bare-metal stent ( $n=297,0.6 \%$ ), those with concomitant use of $1 \mathrm{G}-\mathrm{DES}$ and $2 \mathrm{G}$-DES $(n=174,0.4 \%)$, those with normoglycemia $(n=3845$, $8.4 \%)$, those with DM $(n=5291,11.5 \%)$, and those with cardiogenic shock $(n=247,0.5 \%)$ were excluded. Finally, 4997 patients with AMI and prediabetes who underwent successful DES implantation were included in the study. The patients were divided into two groups: the 1G-DES group $(n=726$, 14.5\%; sirolimus-eluting stent (SES; Cypher, Cordis Corp., Miami Lakes, Florida; $n=313,43.1 \%$ ) and paclitaxel-eluting stent (PES, Taxus, Boston Scientific, Natick, Massachusetts; $n=413,56.9 \%))$ and the 2G-DES group $(n=4271,85.5 \%$; zotarolimus-eluting stent (ZES; Resolute Integrity, Medtronic, Inc., Minneapolis, MN; $n=1466,34.3 \%$ ), everolimus-eluting stent (EES; Xience Prime, Abbott Vascular, Santa Clara, CA; or Promus Element, Boston Scientific, Natick, MA; $n=2132$, 49.9\%), biolimus-eluting stent (BES; BioMatrix Flex, Biosensors International, Morges, Switzerland; or Nobori, Terumo Corporation, Tokyo, Japan; $n=577,13.5 \%$ ), and other stents ( $n=96,2.2 \%)$; Figure 1). The study protocol was approved by the institutional review board of each participating center, and the study was conducted in accordance with the principles of the 1975 Declaration of Helsinki. In this retrospective study, we evaluated patients who had provided written informed consent prior to participation in the KAMIR study. Therefore, any information concerning adverse events of these 4997 participants with AMI and prediabetes including the time intervals and the types of events after the index PCI, which occurred during a 2-year follow-up period, was monitored at the outpatient clinic, by phone calls, or by reviewing their charts at each participating center in those days.
2.2. Percutaneous Coronary Intervention and Medical Treatment. Coronary angiography and PCI were performed in accordance with the general guideline [14]. Before PCI, all the patients received loading doses of aspirin $200-300 \mathrm{mg}$ and clopidogrel 300-600 mg; alternatively, ticagrelor $180 \mathrm{mg}$ or prasugrel $60 \mathrm{mg}$ was administered. Dual antiplatelet therapy (DAPT; a combination of aspirin $100 \mathrm{mg} /$ day with clopidogrel $75 \mathrm{mg} /$ day or ticagrelor $90 \mathrm{mg}$ twice daily or prasugrel 5-10 mg/day) for $>12$ months was recommended for patients who underwent PCI. Administration of triple antiplatelet therapy (cilostazol (Pletal ${ }^{\circledR}$, Otsuka Pharmaceutical Co., Tokyo, Japan) $100 \mathrm{mg}$ twice daily added to DAPT) was left to the discretion of the individual physicians.

2.3. Study Definitions and Clinical Outcomes. Prediabetes was determined based on the medical history and glycated hemoglobin (HbA1c) and fasting plasma glucose (FPG) levels at the index hospitalization and defined as an $\mathrm{HbA} 1 \mathrm{c}$ level of $5.7 \%-6.4 \%$ and an FPG level of $100-125 \mathrm{mg} / \mathrm{dL}$ (5.6-6.9 mmol/L) [15]. ST-segment elevation myocardial infarction (STEMI) and non-STEMI were defined in accordance with the current guidelines $[16,17]$. In NSTEMI cases, an early invasive treatment strategy was defined as performing PCI within 24 hours after admission [17]. A successful PCI was defined as a residual stenosis of $<30 \%$ and thrombolysis in myocardial infarction (TIMI) with grade III flow for the infarct-related artery (IRA) after the procedure. The primary clinical outcome of this study was the occurrence of patient-oriented composite outcomes (POCOs) defined as all-cause death, recurrent myocardial infarction (Re-MI), or any disease revascularization (ADR) at 2-year follow-up. The secondary outcome was definite or probable stent thrombosis (ST) at 2-year follow-up. Allcause death was classified as cardiac death (CD) or nonCD. ADR was composed of target lesion revascularization (TLR), target vessel revascularization (TVR), and nonTVR. The definitions of Re-MI, TLR, TVR, and non-TVR were previously published [18]. The cumulative incidence of ST was defined by current consensus as acute ( 0 to $24 \mathrm{~h})$, subacute ( $24 \mathrm{~h}$ to 30 days), late (30 days to 1 year), and very late (>1 year) [19].

2.4. Statistical Analyses. For continuous variables, in this study, the normality test was performed using the Kolmogorov-Smirnov normality test. According to the normality results, the independent samples $t$-test was applied to examine the difference of continuous variables means of the two groups, and the data were expressed as the mean \pm standard deviations. For categorical variables, the differences between the two groups were analyzed using the chi-squared test or, if not applicable, Fisher's exact test, and the data were expressed as counts and percentages. To adjust for potential confounders, a propensity scorematching (PSM) analysis was performed using a logistic regression model. We tested all available variables listed in Table 1 that could be of potential relevance. The C-statistics for PSM was 0.725 in the current study. Patients in the $1 \mathrm{G}-$ DES group were then one-to-one matched to those in the 


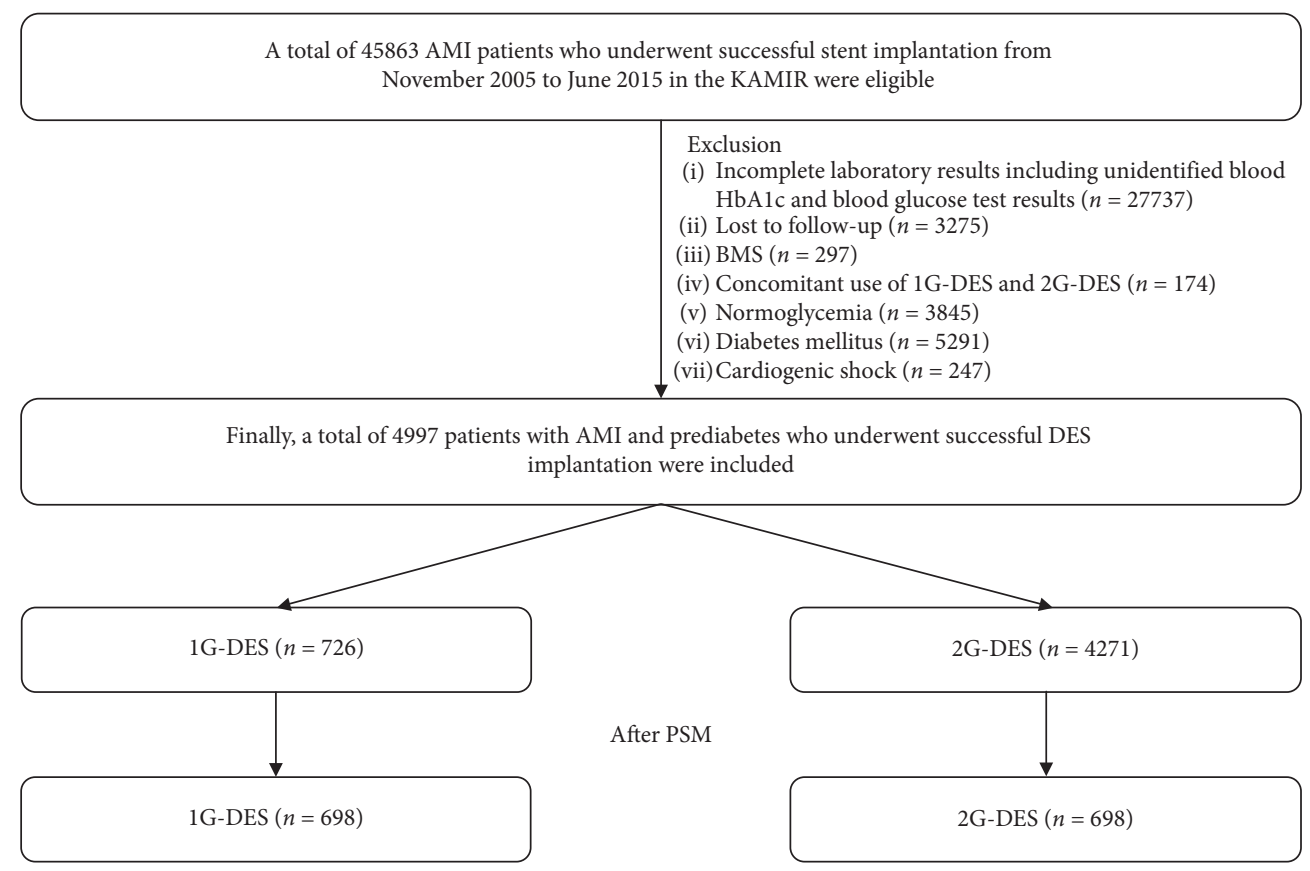

FIgURE 1: Study flowchart. AMI: acute myocardial infarction; KAMIR: Korea AMI Registry; HbA1c: hemoglobin A1c; BMS: bare-metal stent; 1G: first-generation; 2G: second-generation; DES: drug-eluting stent; PSM: propensity score-matching analysis.

TABLE 1: Baseline clinical, laboratory, and procedural characteristics.

\begin{tabular}{|c|c|c|c|c|c|c|}
\hline \multirow{2}{*}{ Variables } & \multicolumn{3}{|c|}{ All patients } & \multicolumn{3}{|c|}{ Propensity score-matched patients } \\
\hline & 1G-DES $(n=726)$ & 2G-DES $(n=4271)$ & $p$ value & 1G-DES $(n=698)$ & 2G-DES $(n=698)$ & $p$ value \\
\hline Age (years) & $63.8 \pm 12.1$ & $64.2 \pm 12.4$ & 0.464 & $63.9 \pm 12.0$ & $63.7 \pm 12.8$ & 0.814 \\
\hline Men, $n(\%)$ & $535(73.7)$ & $3169(74.2)$ & 0.773 & $516(73.9)$ & $520(74.5)$ & 0.854 \\
\hline $\operatorname{LVEF}(\%)$ & $52.6 \pm 12.4$ & $52.4 \pm 11.2$ & 0.798 & $52.7 \pm 12.54$ & $52.4 \pm 11.5$ & 0.618 \\
\hline BMI $\left(\mathrm{kg} / \mathrm{m}^{2}\right)$ & $24.1 \pm 3.1$ & $24.1 \pm 3.3$ & 0.854 & $24.1 \pm 2.9$ & $24.1 \pm 3.1$ & 0.927 \\
\hline SBP (mmHg) & $133.7 \pm 24.8$ & $132.3 \pm 25.2$ & 0.150 & $133.2 \pm 24.2$ & $134.1 \pm 25.5$ & 0.502 \\
\hline $\mathrm{DBP}(\mathrm{mmHg})$ & $82.0 \pm 14.5$ & $80.1 \pm 15.0$ & 0.003 & $81.5 \pm 13.9$ & $81.6 \pm 15.7$ & 0.866 \\
\hline STEMI, $n(\%)$ & $405(55.8)$ & $2442(57.2)$ & 0.484 & $391(56.0)$ & $394(56.4)$ & 0.871 \\
\hline Primary PCI, $n(\%)$ & $376 / 405(92.8)$ & $2346 / 2442(96.1)$ & 0.003 & $363 / 391(92.8)$ & $371 / 394(94.2)$ & 0.452 \\
\hline NSTEMI, $n(\%)$ & $321(44.2)$ & $1829(42.8)$ & 0.484 & $307(44.0)$ & $304(43.6)$ & 0.871 \\
\hline PCI within 24 hours & $246 / 321(76.6)$ & $1563 / 1829(85.5)$ & $<0.001$ & 239/307 (77.9) & $239 / 304(78.6)$ & 0.818 \\
\hline CPR on admission & $17(2.3)$ & $181(4.2)$ & 0.013 & $17(2.4)$ & $16(2.3)$ & 0.860 \\
\hline Hypertension, $n(\%)$ & $362(49.9)$ & $2087(48.9)$ & 0.619 & $351(50.3)$ & $346(49.6)$ & 0.789 \\
\hline Dyslipidemia, $n(\%)$ & $70(9.6)$ & $503(11.8)$ & 0.095 & $70(10.0)$ & $72(10.3)$ & 0.859 \\
\hline Previous MI, $n(\%)$ & $20(2.8)$ & $131(3.1)$ & 0.649 & $19(2.7)$ & $15(2.1)$ & 0.603 \\
\hline Previous PCI, $n(\%)$ & $41(5.6)$ & $228(5.3)$ & 0.733 & $40(5.7)$ & $33(4.7)$ & 0.471 \\
\hline Previous CABG, $n(\%)$ & $3(0.4)$ & $13(0.3)$ & 0.631 & $3(0.4)$ & $2(0.3)$ & 0.654 \\
\hline Previous CVA, $n(\%)$ & $45(6.2)$ & $253(5.9)$ & 0.773 & $43(6.2)$ & $37(5.3)$ & 0.565 \\
\hline Previous HF, $n(\%)$ & $8(1.1)$ & $48(1.1)$ & 0.959 & $8(1.1)$ & $5(0.7)$ & 0.579 \\
\hline Current smokers, $n(\%)$ & $293(40.4)$ & $1875(43.98)$ & 0.075 & $280(40.1)$ & $307(44.0)$ & 0.143 \\
\hline Peak CK-MB (mg/dL) & $127.8 \pm 208.2$ & $136.4 \pm 196.5$ & 0.278 & $129.4 \pm 210.2$ & $119.5 \pm 141.6$ & 0.301 \\
\hline Peak troponin-I (ng/mL) & $39.3 \pm 88.9$ & $46.1 \pm 120.4$ & 0.178 & $40.4 \pm 83.0$ & $39.7 \pm 59.3$ & 0.869 \\
\hline NT-proBNP (pg/mL) & $2141.2 \pm 5100.7$ & $1852.1 \pm 4784.8$ & 0.232 & $2044.5 \pm 4062.4$ & $1997.2 \pm 3788.8$ & 0.821 \\
\hline hs-CRP (mg/dL) & $12.9 \pm 36.8$ & $9.7 \pm 53.4$ & 0.145 & $12.1 \pm 31.3$ & $14.1 \pm 85.9$ & 0.550 \\
\hline Serum creatinine $(\mathrm{mg} / \mathrm{L})$ & $1.11 \pm 1.03$ & $1.10 \pm 1.52$ & 0.935 & $1.11 \pm 1.03$ & $1.22 \pm 2.77$ & 0.314 \\
\hline Serum glucose $(\mathrm{mg} / \mathrm{dL})$ & $149.3 \pm 48.9$ & $150.4 \pm 50.8$ & 0.590 & $149.1 \pm 47.6$ & $151.4 \pm 49.9$ & 0.381 \\
\hline Total cholesterol (mg/dL) & $188.1 \pm 43.4$ & $186.9 \pm 44.4$ & 0.494 & $187.9 \pm 43.3$ & $185.8 \pm 42.0$ & 0.360 \\
\hline Triglyceride $(\mathrm{mg} / \mathrm{L})$ & $117.9 \pm 75.6$ & $131.9 \pm 102.2$ & $<0.001$ & $118.8 \pm 75.7$ & $120.3 \pm 67.1$ & 0.698 \\
\hline HDL cholesterol (mg/L) & $45.0 \pm 12.8$ & $43.6 \pm 15.4$ & 0.020 & $44.8 \pm 12.3$ & $44.1 \pm 15.4$ & 0.380 \\
\hline LDL cholesterol (mg/L) & $121.0 \pm 36.7$ & $119.5 \pm 43.3$ & 0.361 & $120.7 \pm 38.6$ & $118.7 \pm 36.1$ & 0.300 \\
\hline \multicolumn{7}{|l|}{ Discharge medications } \\
\hline Aspirin, $n(\%)$ & $684(94.2)$ & $4119(96.4)$ & 0.004 & $658(94.3)$ & $654(93.7)$ & 0.653 \\
\hline Clopidogel, $n(\%)$ & $707(97.4)$ & $3674(86.0)$ & $<0.001$ & $680(97.4)$ & $680(97.4)$ & 1.000 \\
\hline
\end{tabular}


TABle 1: Continued.

\begin{tabular}{|c|c|c|c|c|c|c|}
\hline \multirow{2}{*}{ Variables } & \multicolumn{3}{|c|}{ All patients } & \multicolumn{3}{|c|}{ Propensity score-matched patients } \\
\hline & 1G-DES $(n=726)$ & 2G-DES $(n=4271)$ & $p$ value & 1G-DES $(n=698)$ & 2G-DES $(n=698)$ & $p$ value \\
\hline Ticagrelor, $n(\%)$ & $3(0.4)$ & $363(8.5)$ & $<0.001$ & $3(0.4)$ & $4(0.6)$ & 0.705 \\
\hline Prasugrel, $n(\%)$ & $2(0.3)$ & $194(4.5)$ & $<0.001$ & $2(0.3)$ & $2(0.3)$ & 1.000 \\
\hline Cilostazol, $n(\%)$ & $217(29.9)$ & $812(19.0)$ & $<0.001$ & $197(28.2)$ & $213(30.5)$ & 0.378 \\
\hline $\mathrm{BB}, n(\%)$ & $573(78.9)$ & $3552(83.2)$ & 0.005 & $552(79.1)$ & $571(81.8)$ & 0.200 \\
\hline ACEI, $n(\%)$ & $419(57.7)$ & $2311(54.1)$ & 0.071 & $396(56.7)$ & $393(56.3)$ & 0.871 \\
\hline $\mathrm{ARB}, n(\%)$ & $178(24.5)$ & $1101(25.8)$ & 0.472 & $174(24.9)$ & $171(24.5)$ & 0.901 \\
\hline $\mathrm{CCB}, n(\%)$ & $54(7.4)$ & $240(5.6)$ & 0.054 & $48(6.9)$ & $50(7.2)$ & 0.917 \\
\hline Lipid-lowering agents, $n(\%)$ & $535(73.7)$ & $3673(86.0)$ & $<0.001$ & $530(75.9)$ & $542(77.7)$ & 0.447 \\
\hline \multicolumn{7}{|l|}{ Infarct-related artery } \\
\hline Left main, $n(\%)$ & $18(2.5)$ & $77(1.8)$ & 0.217 & $14(2.0)$ & $168(2.3)$ & 0.712 \\
\hline $\mathrm{LAD}, n(\%)$ & $363(50.0)$ & $2147(50.3)$ & 0.878 & $349(50.0)$ & $340(48.7)$ & 0.630 \\
\hline $\mathrm{LCx}, n(\%)$ & $134(18.5)$ & $706(16.5)$ & 0.199 & $130(18.6)$ & $128(18.3)$ & 0.890 \\
\hline RCA, $n(\%)$ & $211(29.1)$ & $1341(31.4)$ & 0.209 & $204(29.2)$ & $213(30.5)$ & 0.590 \\
\hline \multicolumn{7}{|l|}{ Treated vessel } \\
\hline Left main, $n(\%)$ & $25(3.4)$ & $127(3.0)$ & 0.495 & $21(3.0)$ & $24(3.4)$ & 0.649 \\
\hline $\mathrm{LAD}, n(\%)$ & $443(61.0)$ & $2537(59.4)$ & 0.411 & $424(60.7)$ & $434(62.2)$ & 0.582 \\
\hline $\mathrm{LCx}, n(\%)$ & $207(28.5)$ & $1106(25.9)$ & 0.139 & $197(28.2)$ & $191(27.4)$ & 0.720 \\
\hline RCA, $n(\%)$ & $262(36.1)$ & $1624(38.0)$ & 0.320 & $255(36.5)$ & $265(38.0)$ & 0.580 \\
\hline \multicolumn{7}{|l|}{ ACC/AHA lesion type } \\
\hline Type B1, $n(\%)$ & $113(15.6)$ & $580(13.6)$ & 0.153 & $110(15.8)$ & $115(16.5)$ & 0.716 \\
\hline Type B2, $n(\%)$ & $237(32.6)$ & $1367(32.0)$ & 0.734 & $226(32.4)$ & $231(33.1)$ & 0.776 \\
\hline Type C, $n(\%)$ & $266(36.6)$ & $1877(43.9)$ & $<0.001$ & $262(37.5)$ & $248(35.5)$ & 0.436 \\
\hline \multicolumn{7}{|l|}{ Extent of CAD } \\
\hline 1-vessel, $n(\%)$ & $321(44.2)$ & $2165(50.7)$ & $<0.001$ & $303(43.4)$ & $296(42.4)$ & 0.705 \\
\hline 2-vessel, $n(\%)$ & $224(30.9)$ & $1326(31.0)$ & 0.917 & $217(31.1)$ & $242(34.7)$ & 0.154 \\
\hline$\geq 3$-vessel, $n(\%)$ & $181(24.9)$ & $780(18.3)$ & $<0.001$ & $171(24.5)$ & $160(22.9)$ & 0.489 \\
\hline IVUS & $177(24.4)$ & $1007(23.6)$ & 0.638 & $172(24.6)$ & $159(22.8)$ & 0.413 \\
\hline OCT & $0(0.0)$ & $33(0.8)$ & 0.017 & $0(0.0)$ & $0(0.0)$ & - \\
\hline FFR & $1(0.1)$ & $59(1.4)$ & 0.004 & $1(0.1)$ & $0(0.0)$ & 0.317 \\
\hline \multicolumn{7}{|l|}{ Stents } \\
\hline SES, $n(\%)$ & $313(43.1)$ & & & $303(43.4)$ & & \\
\hline PES, $n(\%)$ & $413(56.9)$ & & & $395(56.6)$ & & \\
\hline ZES, $n(\%)$ & & $1466(34.3)$ & & & $237(34.0)$ & \\
\hline EES, $n(\%)$ & & $2132(49.9)$ & & & $366(52.4)$ & \\
\hline BES, $n(\%)$ & & $577(13.5)$ & & & $73(10.5)$ & \\
\hline Others, $n(\%)$ & & $96(2.2)$ & & & $22(3.1)$ & \\
\hline Stent diameter $(\mathrm{mm})$ & $3.13 \pm 0.42$ & $3.13 \pm 0.42$ & 0.987 & $3.13 \pm 0.41$ & $3.14 \pm 0.43$ & 0.592 \\
\hline Stent length $(\mathrm{mm})$ & $25.9 \pm 7.15$ & $26.9 \pm 11.5$ & 0.031 & $25.9 \pm 7.06$ & $25.9 \pm 10.0$ & 0.907 \\
\hline Number of stents & $1.54 \pm 0.84$ & $1.48 \pm 0.80$ & 0.051 & $1.54 \pm 0.80$ & $1.55 \pm 0.84$ & 0.740 \\
\hline \multicolumn{7}{|c|}{$\begin{array}{l}\text { Values are means } \pm \text { SD or numbers and percentages. The } p \text { values for categorical data were obtained from the chi-square or Fisher's exact test. For } \\
\text { continuous variables, differences between the two groups were evaluated with independent samples } t \text {-test. LVEF: left ventricular ejection fraction; } \\
\text { BMI: body mass index; SBP: systolic blood pressure; DBP: diastolic blood pressure; STEMI: ST-segment elevation myocardial infarction; NSTEMI: } \\
\text { non-ST-segment elevation myocardial infarction; PCI: percutaneous coronary intervention; CPR: cardiopulmonary resuscitation; CABG: coronary } \\
\text { artery bypass graft; CVA: cerebrovascular events; HF: heart failure; CK-MB: creatine kinase myocardial band; NT-proBNP: N-terminal pro-brain } \\
\text { natriuretic peptide; hs-CRP: high-sensitivity C-reactive protein; HDL: high-density lipoprotein; LDL: low-density lipoprotein; BB: beta-blocker; } \\
\text { ACEI: angiotensin-converting enzyme inhibitors; ARB: angiotensin receptor blocker; CCB: calcium channel blockers; LAD: left anterior descending } \\
\text { coronary artery; LCx: left circumflex coronary artery; RCA: right coronary artery; ACC/AHA: American College of Cardiology/American Heart } \\
\text { Association; CAD: coronary artery disease; IVUS: intravascular ultrasound; OCT: optical coherence tomography; FFR: fractional flow reserve; SES: } \\
\text { sirolimus-eluting stent; PES: paclitaxel-eluting stent; ZES: zotarolimus-eluting stent; EES: everolimus-eluting stent; BES: biolimus-eluting stent. }\end{array}$} \\
\hline
\end{tabular}

2G-DES group according to propensity scores with the nearest available pair-matching method. Subjects were matched with a caliper width equal to 0.01 . The procedure yielded 698 matched pairs. Various clinical outcomes were estimated using the Kaplan-Meier method, and differences between the two groups were compared using the log-rank test. For all analyses, two-sided values of $p<0.05$ were considered statistically significant. All statistical analyses were performed using the SPSS version 20 software (IBM; Armonk, NY, USA).

\section{Results}

3.1. Baseline Characteristics. The baseline clinical, laboratory, and procedural characteristics of the study population are summarized in Table 1 . The mean age $(63.8 \pm 12.1$ years 
vs. $64.2 \pm 12.4$ years, $p=0.464)$ and proportion of men $(73.7 \%$ vs. $74.2 \%, p=0.773)$ of the enrolled patients were similar between the two groups. The mean left ventricular ejection fraction (LVEF) was not significantly different between the two groups $(52.6 \% \pm 12.4 \%$ vs. $52.4 \% \pm 11.2 \%$, $p=0.798)$ and was $>50 \%$ in both groups. However, the proportion of patients who underwent primary PCI (92.8\% vs. $96.1 \%, p=0.003)$ or PCI within 24 hours $(76.6 \%$ vs. $85.5 \%, p<0.001)$ was significantly higher in the $2 \mathrm{G}$-DES group than in the 1G-DES group. The proportion of patients with cardiopulmonary resuscitation $(\mathrm{CPR})$ on admission $(4.2 \%$ vs. $2.3 \%, p=0.013)$ and the prescription rates of aspirin, ticagrelor, prasugrel, and lipid-lowering agents as discharge medications; the number of American College of Cardiology/American Heart Association (ACC/ AHA) type $\mathrm{C}$ lesions; the incidence of single-vessel disease; the use frequency of optical coherence tomography and fractional flow reserve; and the mean total length of the deployed stents were significantly greater in the 2G-DES group than in the 1G-DES group. By contrast, the prescription rates of clopidogrel and cilostazol as discharge medications and the incidence of $\geq 3$-vessel disease were significantly higher in the $1 \mathrm{G}$-DES group than in the $2 \mathrm{G}$ DES group. However, these intergroup differences in baseline characteristics were well balanced after PSM adjustment.

3.2. Clinical Outcomes. The cumulative incidences of major clinical outcomes at 2 years are listed in Table 2 and Figure 2. After PSM analysis, the cumulative incidence rates of POCOs (hazard ratio (HR): 1.467; 95\% confidence interval (CI): $1.068-2.015 ; p=0.018$ ), ADR (HR: $2.259 ; 95 \%$ CI: $1.397-3.654 ; p=0.001$ ), and ST (HR: $4.361 ; 95 \%$ CI: $1.243-15.30 ; p=0.021$ ) were significantly higher in the $1 \mathrm{G}-$ DES group than in the 2G-DES group. However, the cumulative incidence rates of all-cause death, $\mathrm{CD}$, and Re-MI were similar between the two groups. Table 3 shows the independent predictors of POCOs and ADR at 2 years. Old age ( $\geq 65$ years), LVEF of $<50 \%$, CPR on admission, use of a lipid-lowering agent, and multivessel disease were significant independent predictors of POCOs. In addition, multivessel disease was a significant independent predictor of ADR in this study.

\section{Discussion}

The main findings of this study are as follows: (1) the cumulative incidence rates of POCOs, ADR, and ST were significantly higher in the 1G-DES group than in the 2GDES group; (2) the cumulative incidence rates of all-cause death, CD, and Re-MI were similar between the two groups; (3) Multivessel disease was a common independent predictor of both POCOs and ADR.

$1 \mathrm{G}-\mathrm{DES}$ is made of stainless steel with a closed-cell design and has a relatively thick inner diameter $(130-150 \mu \mathrm{m})$, making them difficult to maneuver through significantly diseased and calcified vessels. In addition, the major serious problem of the $1 \mathrm{G}-\mathrm{DES}$ was the occurrence of (very) late ST, induced by the polymer or even by the stent material itself [20]. By contrast, the 2G-DES is made of cobalt-chromium ( $\mathrm{CoCr}$ ) and has thinner stent struts $(50-90 \mu \mathrm{m})$ and showed improved ability for deliverability while maintaining an adequate radial strength [21]. The polymers in the $2 \mathrm{G}-\mathrm{DES}$ were more biocompatible and thromboresistant than those in the 1G-DES [22] One meta-analysis revealed that CoCr-EESs were associated with significantly lower rates of definite ST than PESs (odds ratio (OR): 0.34, 95\% CI: 0.19-0.62) [23]. With regard to diabetes, Bavishi et al. [24] performed a meta-analysis of randomized trials to compare the efficacy and safety between the 1G-DES and the 2G-DES. In their study, the EES showed significantly decreased incidence rates of major adverse cardiac events by $18 \%$ (relative risk (RR)): $0.82,95 \%$ CI: $0.70-0.96$ ) and ST by $46 \%$ (RR: 0.54 , 95\% CI: 0.35-0.82) as compared with the 1GDES. Moreover, the EES showed a trend toward reduced incidence rates of TLR and TVR $(p=0.05)$. The ZES was associated with $89 \%$ increased risk of TLR (RR: 1.89 , 95\% CI: 1.10-3.22) as compared with the 1G-DES in their study. The results of our study may be similar to those of their study. However, their study population was not confined to patients with AMI.

Higher blood glucose level was an important factor of increased risk of death and poor clinical outcome after AMI [25-27]. Kowalczyk et al. [28] reported that patients with HbAlc levels of $\leq 5.9 \%$ had significantly lower posthospital mortality (4.5\%) than those with HbAlc levels of $>5.9 \%$ $(25.0 \% ; p<0.001)$ in 2146 AMI survivors. However, the evident underlying pathological mechanisms related to the adverse clinical outcomes in hyperglycemia status remain unclear. Liu et al. [29] suggested that elevated glucose level is associated with the development of endothelial dysfunction. Moreover, this endothelial dysfunction is the leading cause of platelet activation [30]. In addition, hyperglycemia plays an important role in the development of diabetic macrovascular complications, including atherosclerosis and restenosis [31]. Patients with diabetes have more diffuse disease that often rapidly progresses and tend to have exaggerated neointimal hyperplasia and increased need for repeat revascularization [32]. Moreover, glycosylation of vascular collagen and elastin is thought to lead to a more diffuse pattern of restenosis [33].

Even though the 2G-DES uses an evolved stent platform and a more biocompatible polymer than that in the 1G-DES, data concerning the outcomes between the two DESs in patients with AMI are conflicting [10,34]. With regard to diabetes, the relative superiority between the $1 \mathrm{G}-\mathrm{DES}$ and the 2G-DES in patients with diabetes is controversial [35-37]. Furthermore, in patients with prediabetes, limited follow-up data are available regarding the comparative long-term effects of 1G-DES and 2G-DES implantation. Even though the study population, follow-up duration, and definition of prediabetes were different between in our study and that of Kok et al. [38], clinical outcomes were compared between prediabetes and diabetes $(11.1 \%$ vs. $10.5 \%)$. Therefore, the major clinical outcomes of our study could reflect the meta-analysis results of the study of Bavishi et al. [24].

$\mathrm{ST}$ is another controversial issue in the DES era. In our study, unexpectedly, the cumulative incidence of very late ST 
TABle 2: Clinical outcomes by Kaplan-Meier analysis and Cox proportional hazard ratio analysis at 2 years.

\begin{tabular}{|c|c|c|c|c|c|}
\hline Outcomes & 1G-DES & 2G-DES & Log-rank & Hazard ratio $(95 \% \mathrm{CI})$ & $p$ value \\
\hline \multicolumn{6}{|l|}{ All patients } \\
\hline POCOs & $100(13.9)$ & $353(8.8)$ & $<0.001$ & $1.616(1.294-2.017)$ & $<0.001$ \\
\hline All-cause death & $43(5.9)$ & $171(4.2)$ & 0.035 & $1.431(1.024-1.999)$ & 0.036 \\
\hline Cardiac death & $34(4.7)$ & $129(3.1)$ & 0.030 & $1.514(1.037-2.209)$ & 0.032 \\
\hline Re-MI & $9(1.3)$ & $79(2.0)$ & 0.192 & $1.576(0.791-3.141)$ & 0.196 \\
\hline Death or MI & $52(7.2)$ & $244(6.0)$ & 0.224 & $1.204(0.892-1.624)$ & 0.225 \\
\hline${ }^{\mathrm{a}}$ Any disease revascularization & $58(8.4)$ & $138(3.6)$ & $<0.001$ & $2.383(1.752-3.238)$ & $<0.001$ \\
\hline Stent thrombosis (probable or definite) & $14(1.9)$ & $28(0.7)$ & 0.001 & $2.956(1.556-5.615)$ & 0.001 \\
\hline Acute & $1(0.1)$ & $2(0.0)$ & 0.355 & $2.941(0.267-32.44)$ & 0.378 \\
\hline Subacute & $4(0.6)$ & $13(0.3)$ & 0.290 & $1.814(0.591-5.563)$ & 0.298 \\
\hline Late & $7(1.0)$ & $10(0.2)$ & 0.002 & $4.146(1.578-10.89)$ & 0.004 \\
\hline Very late & $2(0.3)$ & $3(0.1)$ & 0.103 & $3.967(0.663-23.74)$ & 0.131 \\
\hline \multicolumn{6}{|l|}{ Propensity score-matched patients } \\
\hline POCOs & $94(13.5)$ & $64(9.5)$ & 0.017 & $1.467(1.068-2.015)$ & 0.018 \\
\hline All-cause death & $42(6.0)$ & $36(5.3)$ & 0.541 & $1.149(0.736-1.793)$ & 0.541 \\
\hline Cardiac death & $33(4.8)$ & $25(3.7)$ & 0.317 & $1.303(0.775-2.191)$ & 0.319 \\
\hline Re-MI & $8(1.2)$ & $8(1.2)$ & 0.971 & $1.019(0.382-2.714)$ & 0.971 \\
\hline Death or MI & $50(7.2)$ & $44(6.5)$ & 0.588 & $1.118(0.746-1.677)$ & 0.588 \\
\hline${ }^{\mathrm{a}}$ Any disease revascularization & $54(8.2)$ & $24(3.7)$ & 0.001 & $2.259(1.397-3.654)$ & 0.001 \\
\hline Stent thrombosis (probable or definite) & $13(1.9)$ & $3(0.4)$ & 0.012 & $4.361(1.243-15.30)$ & 0.021 \\
\hline Acute & $1(0.1)$ & $0(0.0)$ & 0.317 & - & - \\
\hline Subacute & $3(0.4)$ & $1(0.1)$ & 0.316 & $3.006(0.313-28.90)$ & 0.340 \\
\hline Late & $7(1.0)$ & $2(0.3)$ & 0.093 & $3.526(0.733-16.98)$ & 0.116 \\
\hline Very late & $2(0.3)$ & $0(0.0)$ & 0.155 & - & - \\
\hline
\end{tabular}

1G: first-generation; 2G: second-generation; DES: drug-eluting stent; HR: hazard ratio; CI: confidence interval; POCOs: patient-oriented composite outcomes; Re-MI: recurrent myocardial infarction. ${ }^{a}$ Any disease revascularization was composed of target lesion revascularization, target vessel revascularization, and nontarget vessel revascularization.

TABLE 3: Independent predictors for POCOs and any disease revascularization at 2 years in all patients.

\begin{tabular}{|c|c|c|c|c|c|c|c|c|}
\hline \multirow{3}{*}{ Variables } & \multicolumn{4}{|c|}{ POCOs } & \multicolumn{4}{|c|}{ Any disease revascularization } \\
\hline & \multicolumn{2}{|c|}{ Univariate } & \multicolumn{2}{|c|}{ Multivariate } & \multicolumn{2}{|c|}{ Univariate } & \multicolumn{2}{|c|}{ Multivariate } \\
\hline & $\mathrm{HR}(95 \% \mathrm{CI})$ & $p$ value & HR (95\% CI) & $p$ value & HR $(95 \%$ CI $)$ & $p$ value & HR $(95 \%$ CI $)$ & $p$ value \\
\hline 1G-DES vs. $2 \mathrm{G}-\mathrm{DES}$ & $\begin{array}{c}1.616 \\
(1.294-2.017)\end{array}$ & $<0.001$ & $\begin{array}{c}1.520 \\
(1.213-1.905)\end{array}$ & $<0.001$ & $\begin{array}{c}2.383 \\
(1.753-3.238)\end{array}$ & $<0.001$ & $\begin{array}{c}2.228 \\
(1.631-3.043)\end{array}$ & $<0.001$ \\
\hline Age ( $\geq 65$ years) & $\begin{array}{c}1.548 \\
(1.282-1.867)\end{array}$ & $<0.001$ & $\begin{array}{c}1.318 \\
(1.072-1.620)\end{array}$ & 0.009 & $\begin{array}{c}1.024 \\
(0.774-1.355)\end{array}$ & 0.866 & $\begin{array}{c}1.109 \\
(0.812-1.515)\end{array}$ & 0.517 \\
\hline Men & $\begin{array}{c}1.269 \\
(1.039-1.550)\end{array}$ & 0.020 & $\begin{array}{c}1.030 \\
(0.828-1.282)\end{array}$ & 0.789 & $\begin{array}{c}1.097 \\
(0.802-1.501\end{array}$ & 0.563 & $\begin{array}{c}1.072 \\
(0.759-1.515)\end{array}$ & 0.692 \\
\hline LVEF $(<50 \%)$ & $\begin{array}{c}1.652 \\
(1.374-1.986)\end{array}$ & $<0.001$ & $\begin{array}{c}1.437 \\
(1.191-1.733)\end{array}$ & $<0.001$ & $\begin{array}{c}1.037 \\
(0.777-1.383)\end{array}$ & 0.807 & $\begin{array}{c}1.027 \\
(0.767-1.375)\end{array}$ & 0.859 \\
\hline Hypertension & $\begin{array}{c}1.333 \\
(1.107-1.605)\end{array}$ & 0.002 & $\begin{array}{c}1.187 \\
(0.977-1.441)\end{array}$ & 0.084 & $\begin{array}{c}1.249 \\
(0.943-1.654)\end{array}$ & 0.121 & $\begin{array}{c}1.168 \\
(0.870-1.568)\end{array}$ & 0.302 \\
\hline Dyslipidemia & $\begin{array}{c}1.075 \\
(0.811-1.425)\end{array}$ & 0.617 & $\begin{array}{c}1.182 \\
(0.887-1.575)\end{array}$ & 0.252 & $\begin{array}{c}1.240 \\
(0.826-1.862)\end{array}$ & 0.299 & $\begin{array}{c}1.206 \\
(0.798-1.825)\end{array}$ & 0.374 \\
\hline $\mathrm{CPR}$ on admission & $\begin{array}{c}4.004 \\
(3.020-5.309)\end{array}$ & $<0.001$ & $\begin{array}{c}3.722 \\
(2.799-4.950)\end{array}$ & $<0.001$ & $\begin{array}{c}1.625 \\
(0.860-3.071)\end{array}$ & 0.135 & $\begin{array}{c}1.659 \\
(0.875-3.142)\end{array}$ & 0.121 \\
\hline Lipid-lowering agent & $\begin{array}{c}2.487 \\
(2.038-3.035)\end{array}$ & $<0.001$ & $\begin{array}{c}2.355 \\
(1.908-2.857)\end{array}$ & $<0.001$ & $\begin{array}{c}1.503 \\
(1.069-2.114)\end{array}$ & 0.019 & $\begin{array}{c}1.514 \\
(1.073-2.137)\end{array}$ & 0.118 \\
\hline MVD & $\begin{array}{c}1.733 \\
(1.430-2.102)\end{array}$ & $<0.001$ & $\begin{array}{c}1.585 \\
(1.303-1.928)\end{array}$ & $<0.001$ & $\begin{array}{c}1.852 \\
(1.377-2.491)\end{array}$ & $<0.001$ & $\begin{array}{c}1.793 \\
(1.328-2.420)\end{array}$ & $<0.001$ \\
\hline $\begin{array}{l}\text { ACC/AHA type B2/C } \\
\text { lesion }\end{array}$ & $\begin{array}{c}1.141 \\
(0.918-1.419)\end{array}$ & 0.234 & $\begin{array}{c}1.131 \\
(0.905-1.413)\end{array}$ & 0.278 & $\begin{array}{c}1.014 \\
(0.738-1.392)\end{array}$ & 0.933 & $\begin{array}{c}1.062 \\
(0.768-1.469)\end{array}$ & 0.715 \\
\hline $\begin{array}{l}\text { Stent diameter } \\
(<3.0 \mathrm{~mm})\end{array}$ & $\begin{array}{c}1.176 \\
(0.967-1.431)\end{array}$ & 0.104 & $\begin{array}{c}1.088 \\
(0.891-1.328)\end{array}$ & 0.407 & $\begin{array}{c}1.097 \\
(0.812-1.482)\end{array}$ & 0.548 & $\begin{array}{c}1.031 \\
(0.760-1.400)\end{array}$ & 0.843 \\
\hline Stent length ( $\geq 28 \mathrm{~mm})$ & $\begin{array}{c}1.174 \\
(0.975-1.413)\end{array}$ & 0.091 & $\begin{array}{c}1.060 \\
(0.877-1.281)\end{array}$ & 0.546 & $\begin{array}{c}1.380 \\
(1.043-1.826)\end{array}$ & 0.024 & $\begin{array}{c}1.332 \\
(1.000-1.774)\end{array}$ & 0.050 \\
\hline
\end{tabular}

POCOs: patient-oriented composite outcomes; HR: hazard ratio; CI, confidence interval; 1G: first-generation; 2G: second-generation; DES: drug-eluting stent; LVEF: left ventricular ejection fraction; CPR: cardiopulmonary resuscitation; MVD: multivessel disease; ACC/AHA: American College of Cardiology/ American Heart Association. 

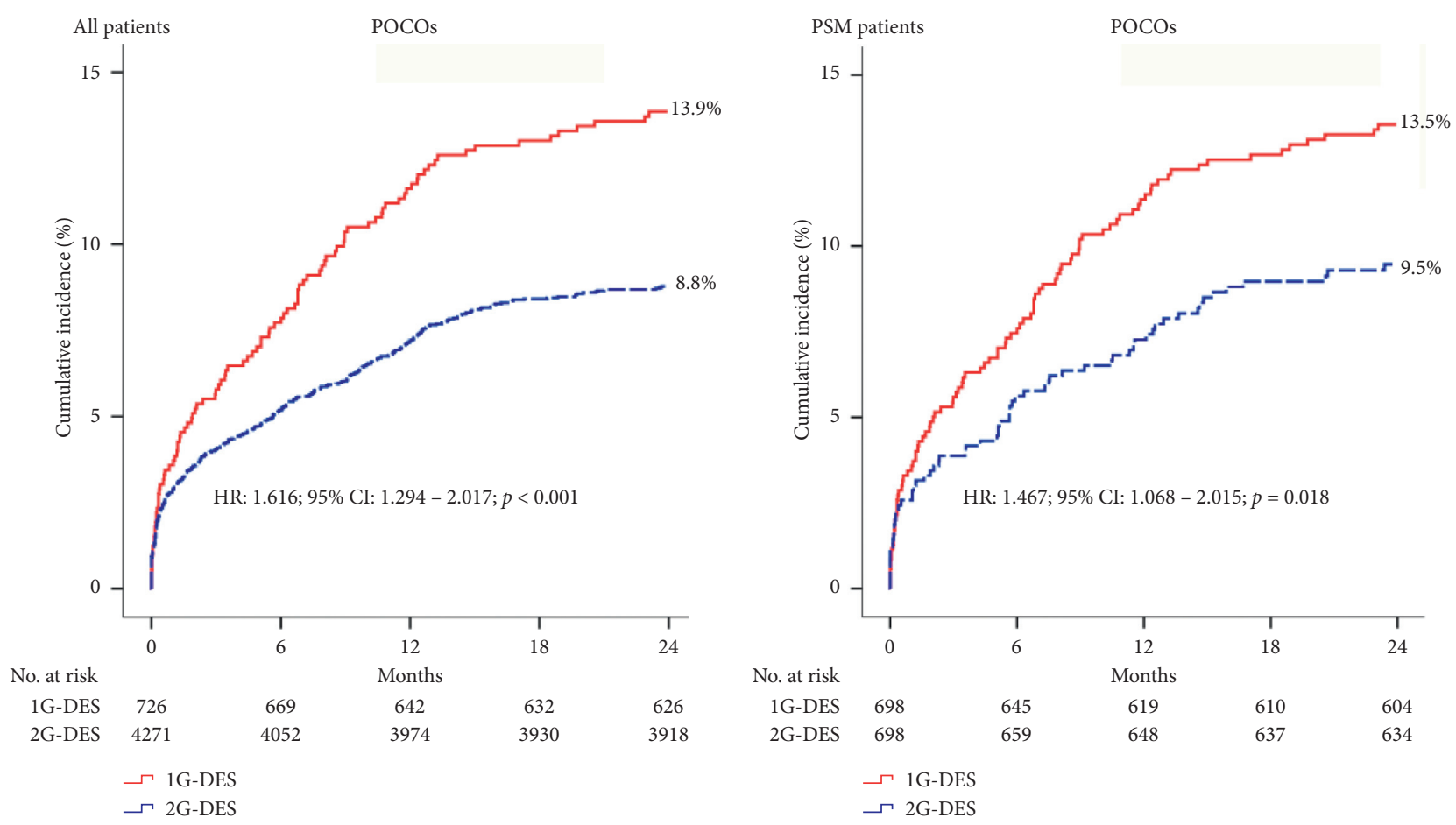

(a)
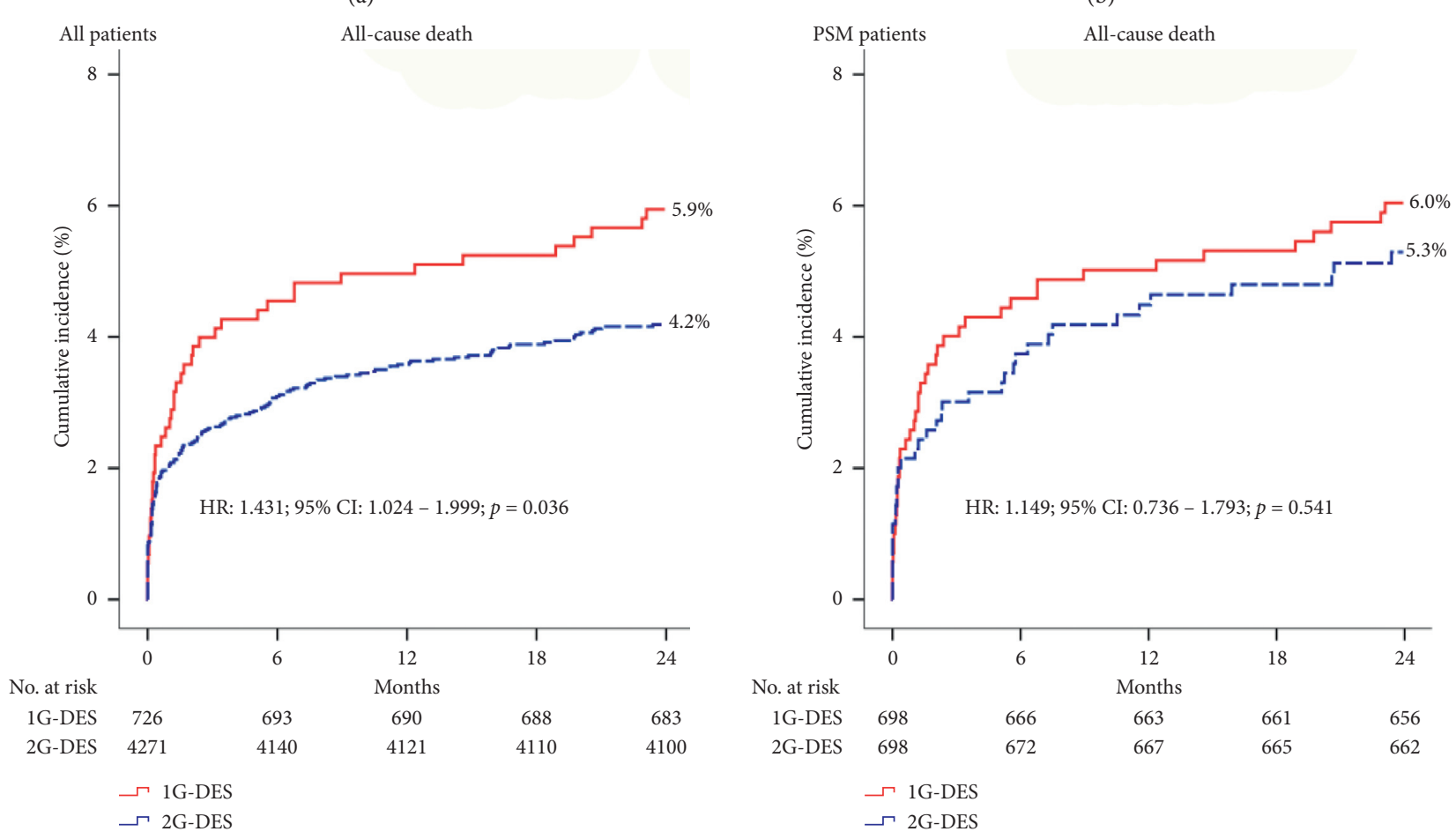

(c)

(d)

Figure 2: Continued. 


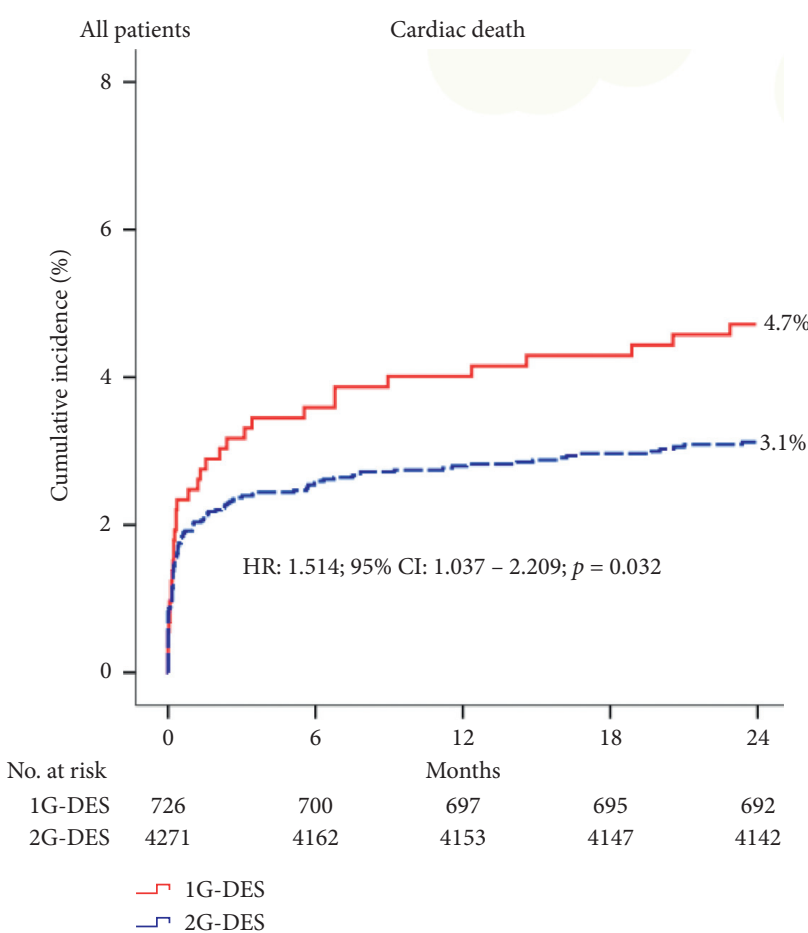

(e)

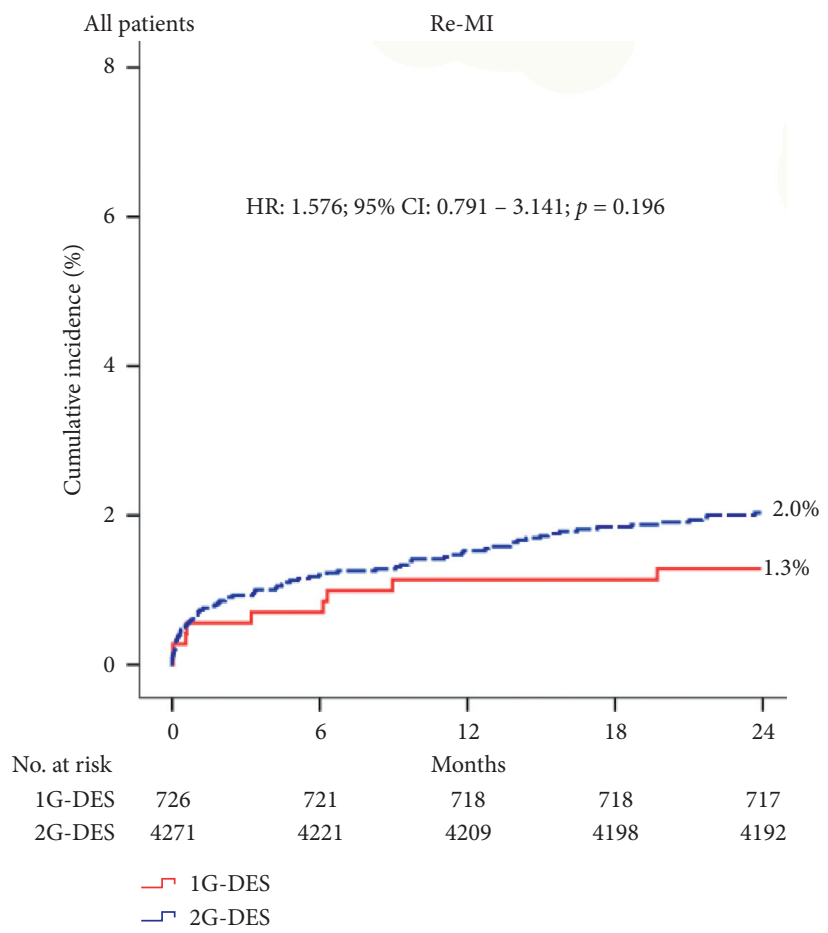

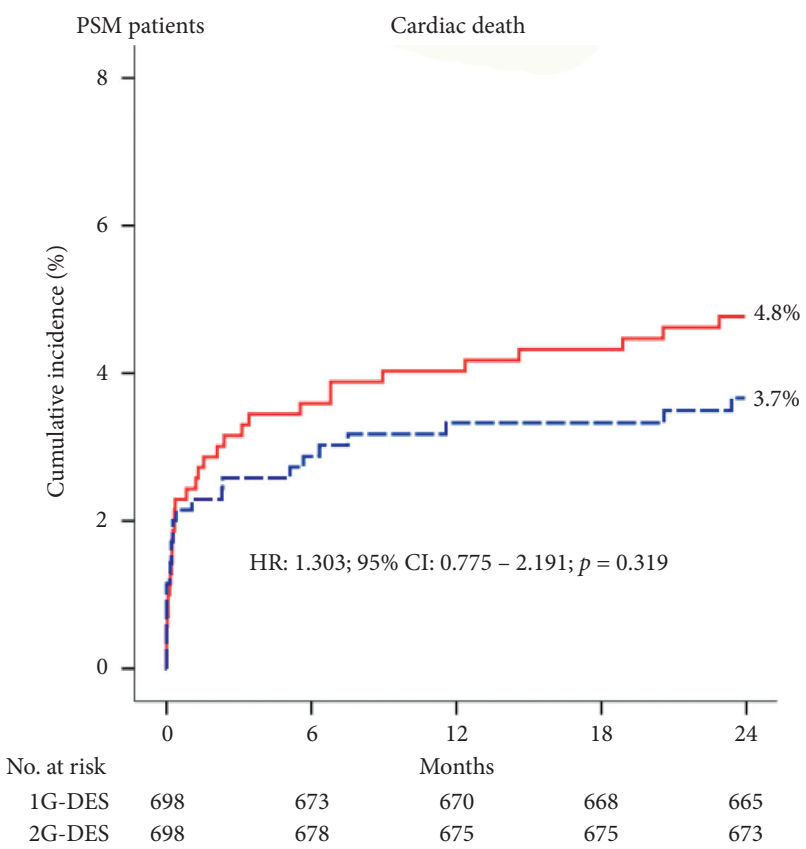

$\neg 1 \mathrm{G}-\mathrm{DES}$

$\neg 2$ G-DES

(f)
PSM patients
Re-MI
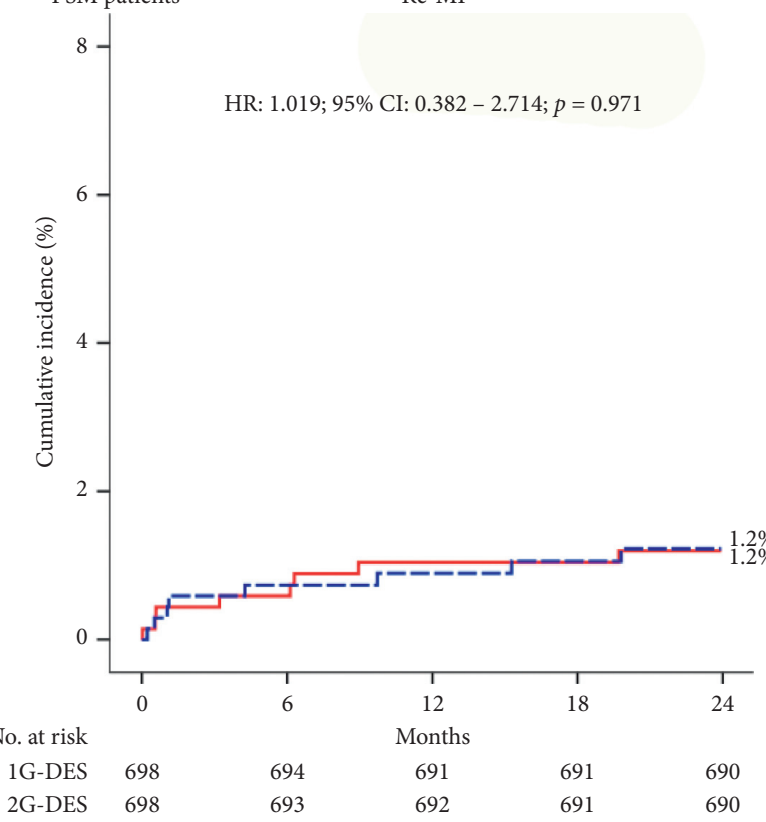

$\neg$ 1G-DES

$\neg$ 2G-DES

(g)

(h)

Figure 2: Continued. 


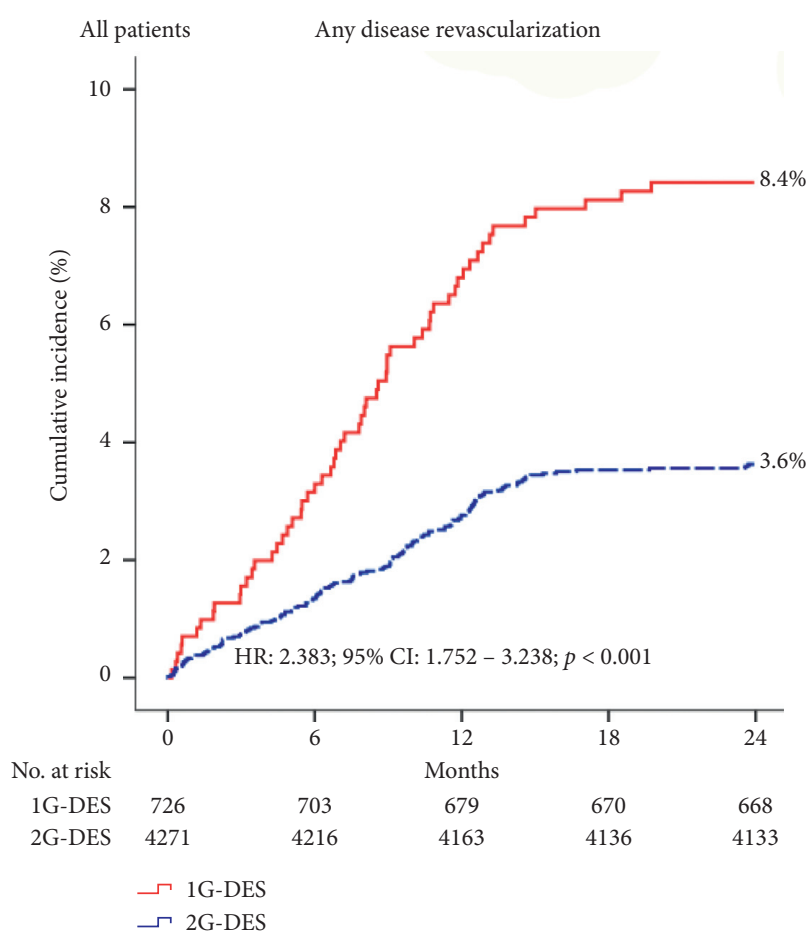

(i)

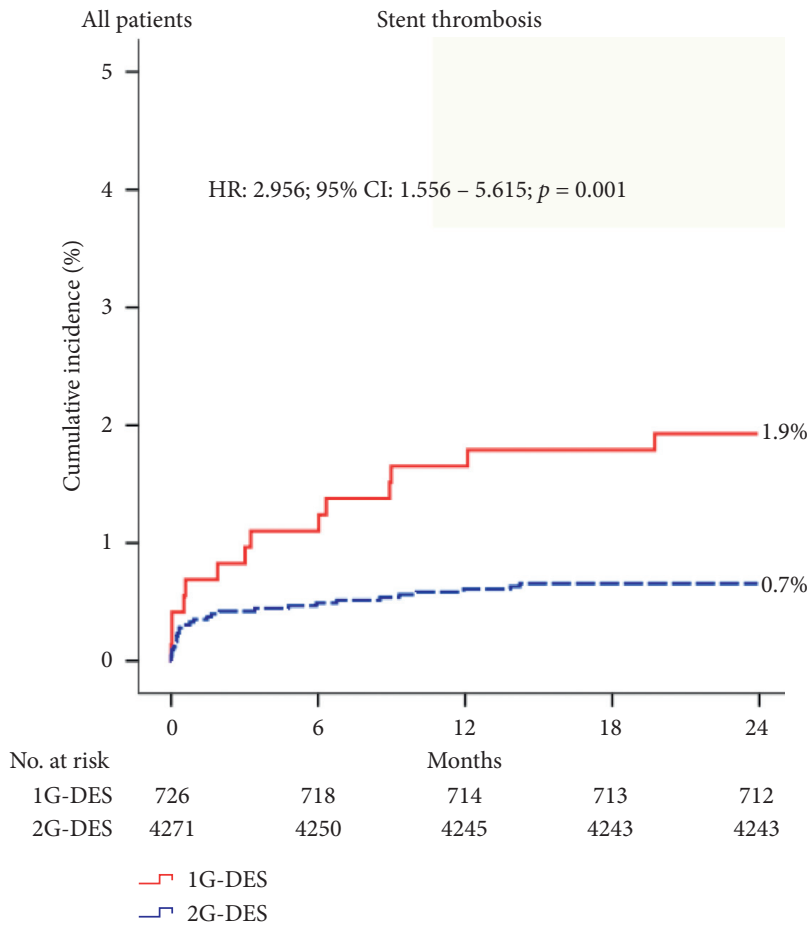

(k)

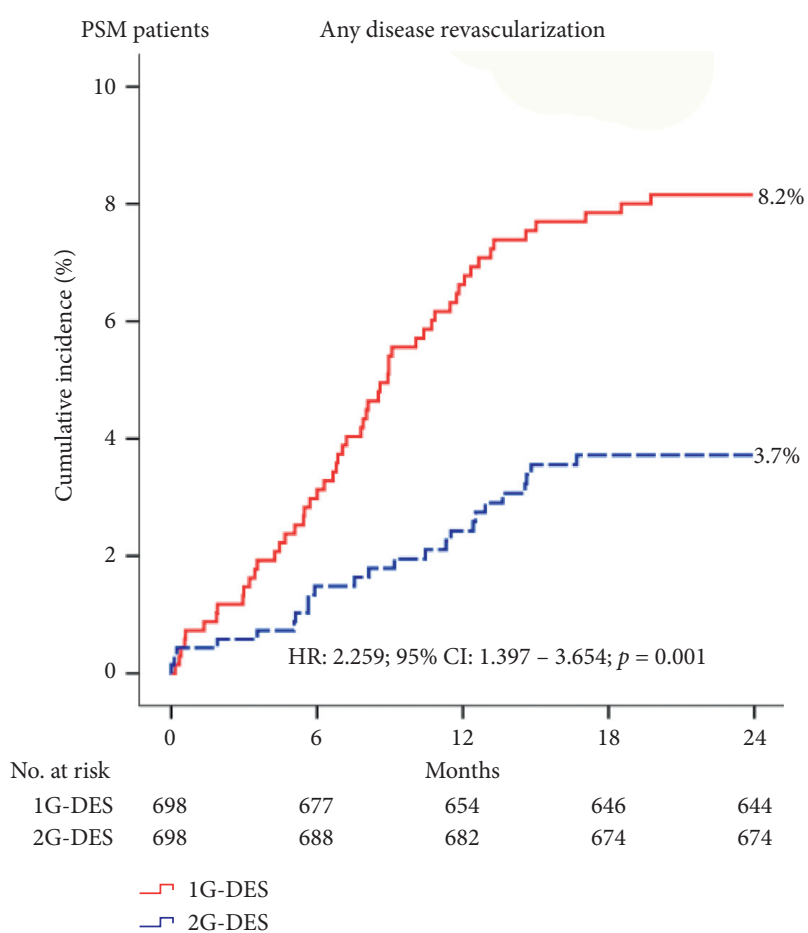

(j)

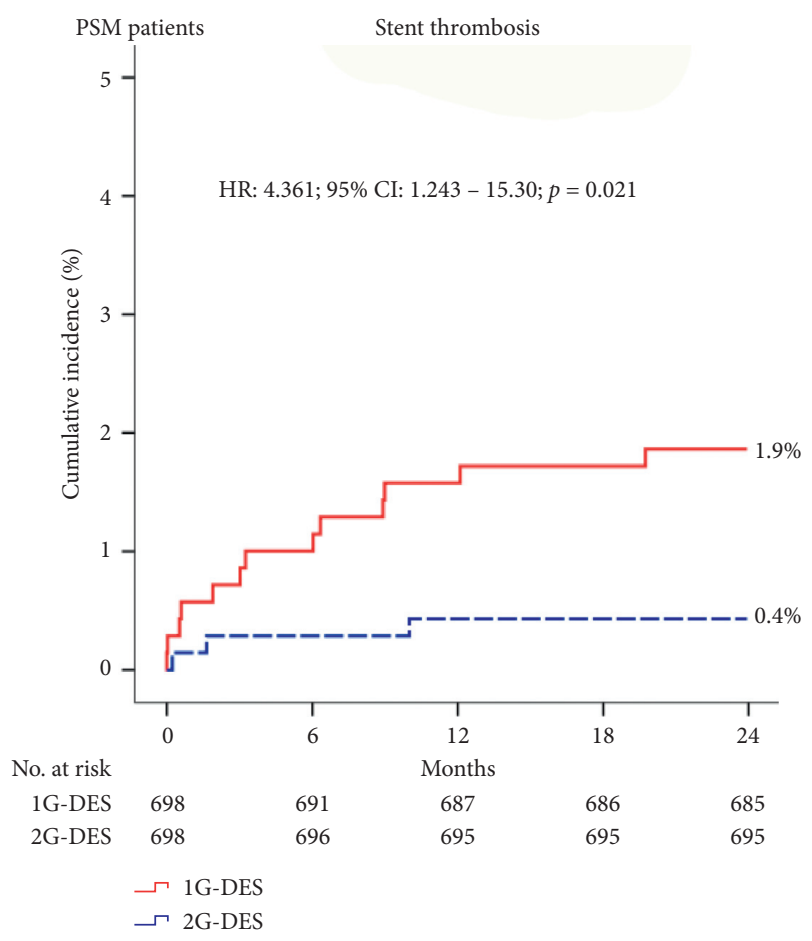

(1)

FIGURe 2: Kaplan-Meier analysis of the incidence rates of POCOs (a, b), all-cause death (c, d), cardiac death (e, f), Re-MI (g, h), any disease revascularization $(i, j)$, and ST $(k, l)$ in all patients $(a, c, e, g, i, k)$ and PSM patients $(b, d, f, h, j, l)$ at 2 years. 1G: first-generation; 2G: secondgeneration; DES: drug-eluting stent; HR: hazard ratio; CI: confidence interval; POCOs: patient-oriented composite outcomes; Re-MI: recurrent myocardial infarction; ST: stent thrombosis; PSM: propensity score-matching analysis.

was similar between the two DES generations. By contrast, late ST was significantly different between the two groups. The main cause of these results may be related to the relatively higher numbers of patients who received EES $(n=$ $2132 / 4271,49.9 \%$ ) in this study population. In the study of Bangalore et al. [39], EES was associated with the lowest 
incidence rates of TVR, Re-MI, and ST as compared with ZES and PES. In the study of Kedhi et al. [35], the difference in the risk of ST was already observed in the early phase and was maintained during the 1-year follow-up. Similarly, in our study, the risk of ST was already determined within 1 year after the index PCI.

Although oral glucose tolerance test (OGTT) is considered more sensitive than measurement of $\mathrm{HbAlclevel} \mathrm{for}$ defining diabetes [15], in this study, prediabetes was determined on the basis of patients' medical history and $\mathrm{HbAlc}$ and FPG levels at the index hospitalization. One of the main advantages of measuring $\mathrm{HbAlc}$ level is that it can be performed at any time because it does not require fasting. This is especially convenient in circumstances in which performing the test and interpreting the result may be difficult in the milieu of an acute illness such as AMI $[38,40]$. Therefore, despite that measurement of $\mathrm{HbA1c}$ level may not be ideal, it can be used as an alternative diagnostic tool for making these important assessments.

In this KAMIR study, $>50$ high-volume university or community hospitals in South Korea participated, but the study population was insufficient to provide meaningful results. Taken together, the results of this study may provide a meaningful message to the interventional cardiologist during PCI to help select the appropriate DES, especially in patients with AMI and prediabetes.

This study has several limitations. First, some data may have been underreported and/or missing owing to the nonrandomized nature of this study. Second, a proportion of the patients with prediabetes (based on $\mathrm{HbAlc}$ level) may be diagnosed with overt diabetes if retested using a more sensitive diagnostic test (e.g., OGTT). This may be a source of bias in the study. Third, the study was based on discharge medications, as we could not confirm the participants' adherence or nonadherence to their antidiabetic drugs. Therefore, we could not discern the degree of glycemic control of the participants during the follow-up period, which might constitute an additional bias in this study. Fourth, the 2-year follow-up period was relatively short for determining the long-term major clinical outcomes; thus, longer follow-up period data are required. Fifth, we performed a PSM analysis to strengthen our results, but variables not included in the KAMIR study may have affected the study outcomes.

In conclusion, with regard to the beneficial effects on POCOs, ADR, and ST reduction capacity, in patient with AMI and prediabetes, 2G-DES implantation was more efficacious than 1G-DES implantation during the 2-year follow-up period. However, further randomized trials are needed to more precisely confirm the superior efficacy of 2G-DES over 1G-DES.

\section{Data Availability}

The data used to support the findings of this study are included within the article and supplementary tables.

\section{Conflicts of Interest}

The authors declare that there are no conflicts of interest regarding the publication of this paper.

\section{Authors' Contributions}

Yong Hoon Kim and Ae-Young Her contributed equally to this work.

\section{Acknowledgments}

The authors thank all of the clinical investigators who contributed time and effort to this study, as well as the Korea Acute Myocardial Infarction (KAMIR) Investigators. This research was supported by a fund (2016-ER6304-02) by Research of Korea Centers for Disease Control and Prevention.

\section{References}

[1] N. N. Wahab, E. A. Cowden, N. J. Pearce, M. J. Gardner, H. Merry, and J. L. Cox, "Is blood glucose an independent predictor of mortality in acute myocardial infarction in the thrombolytic era?" Journal of the American College of Cardiology, vol. 40, no. 10, pp. 1748-1754, 2002.

[2] M. S. Sabatine, C. P. Cannon, C. M. Gibson et al., "Addition of clopidogrel to aspirin and fibrinolytic therapy for myocardial infarction with ST-segment elevation," New England Journal of Medicine, vol. 352, no. 12, pp. 1179-1189, 2005.

[3] D. Planer, B. Witzenbichler, G. Guagliumi et al., "Impact of hyperglycemia in patients with ST-segment elevation myocardial infarction undergoing percutaneous coronary intervention: the HORIZONS-AMI trial," International Journal of Cardiology, vol. 167, no. 6, pp. 2572-2579, 2013.

[4] C. K. Naber, R. H. Mehta, C. Jünger et al., "Impact of admission blood glucose on outcomes of nondiabetic patients with acute ST-elevation myocardial infarction (from the German Acute Coronary Syndromes [ACOS] Registry)," The American Journal of Cardiology, vol. 103, no. 5, pp. 583-587, 2009.

[5] D. E. Cutlip, A. G. Chhabra, D. S. Baim et al., "Beyond restenosis," Circulation, vol. 110, no. 10, pp. 1226-1230, 2004.

[6] I. Iakovou, T. Schmidt, E. Bonizzoni et al., "Incidence, predictors, and outcome of thrombosis after successful implantation of drug-eluting stents," JAMA, vol. 293, no. 17, pp. 2126-2130, 2005.

[7] T. T. Lee, L. Feinberg, D. S. Baim et al., "Effect of diabetes mellitus on five-year clinical outcomes after single-vessel coronary stenting (a pooled analysis of coronary stent clinical trials)," The American Journal of Cardiology, vol. 98, no. 6, pp. 718-721, 2006.

[8] M. K. Ali, K. M. Bullard, S. Saydah, G. Imperatore, and E. W. Gregg, "Cardiovascular and renal burdens of prediabetes in the USA: analysis of data from serial cross-sectional surveys, 1988-2014," The Lancet Diabetes \& Endocrinology, vol. 6, no. 5, pp. 392-403, 2018.

[9] M. Coutinho, H. C. Gerstein, Y. Wang, and S. Yusuf, "The relationship between glucose and incident cardiovascular events. A metaregression analysis of published data from 20 studies of 95,783 individuals followed for 12.4 years," Diabetes Care, vol. 22, no. 2, pp. 233-240, 1999.

[10] S. H. Hofma, P. C. Smits, J. Brouwer et al., "Long-term followup of second-generation everolimus-eluting stents versus first-generation sirolimus-eluting stents in acute myocardial infarction: three-year results of the XAMI trial," EuroIntervention, vol. 10, no. 11, pp. 1280-1283, 2015.

[11] E. Di Lorenzo, R. Sauro, M. Capasso et al., "Long-term results of the randomized comparison of everolimus-eluting stents and sirolimus-eluting stent in patients with ST elevation 
myocardial infarction (RACES-MI trial)," International Journal of Cardiology, vol. 202, pp. 177-182, 2016.

[12] G. De Luca, P. Smits, S. H. Hofma et al., "Everolimus eluting stent vs first generation drug-eluting stent in primary angioplasty: a pooled patient-level meta-analysis of randomized trials," International Journal of Cardiology, vol. 244, pp. 121-127, 2017.

[13] D. S. Sim and M. H. Jeong, "Differences in the Korea acute myocardial infarction registry compared with western registries," Korean Circulation Journal, vol. 47, no. 6, pp. 811-822, 2017.

[14] E. D. Grech, "Percutaneous coronary intervention. II: the procedure," BMJ, vol. 326, no. 7399, pp. 1137-1140, 2003.

[15] E. D. Grech, "Standards of medical care in diabetes-2010," Diabetes Care, vol. 33, no. 1, 2010.

[16] P. T. O'Gara, F. G. Kushner, D. D. Ascheim et al., “ACCF/AHA guideline for the management of ST-elevation myocardial infarction: a report of the American College of Cardiology foundation/American heart association task force on practice guidelines," Diabetes Care, vol. 61, no. 4, pp. e78-e140, 2013.

[17] E. A. Amsterdam, N. K. Wenger, R. G. Brindis et al., "2014 AHA/ACC guideline for the management of patients with nonST-elevation acute coronary syndromes," Journal of the American College of Cardiology, vol. 64, no. 24, pp. e139-e228, 2014.

[18] Y. H. Kim, A.-Y. Her, M. H. Jeong et al., "Impact of reninangiotensin system inhibitors on long-term clinical outcomes in patients with acute myocardial infarction treated with successful percutaneous coronary intervention with drugeluting stents: comparison between STEMI and NSTEMI," Atherosclerosis, vol. 280, pp. 166-173, 2019.

[19] P. K. Bundhun, Z. J. Wu, and M. H. Chen, "Is there any significant difference in stent thrombosis between sirolimus and paclitaxel eluting stents?: a systematic review and metaanalysis of randomized controlled trials," Medicine (Baltimore), vol. 95, no. 5, 2016.

[20] A. M. Galløe, H. Kelbæk, L. Thuesen et al., "SORT OUT II investigators. 10-Year clinical outcome after randomization to treatment by sirolimus- or paclitaxel-eluting coronary stents," Nature Reviews Cardiology, vol. 69, no. 6, pp. 616-624, 2017.

[21] S. Torii, H. Jinnouchi, A. Sakamoto et al., "Drug-eluting coronary stents: insights from preclinical and pathology studies," Nature Reviews Cardiology, vol. 17, no. 1, pp. 37-51, 2019.

[22] G. Sarno, B. Lagerqvist, O. Fröbert et al., "Lower risk of stent thrombosis and restenosis with unrestricted use of 'newgeneration' drug-eluting stents: a report from the nationwide Swedish Coronary Angiography and Angioplasty Registry (SCAAR)," European Heart Journal, vol. 33, no. 5, pp. 606613, 2012.

[23] T. Palmerini, G. Biondi-Zoccai, D. D. Riva et al., "Stent thrombosis with drug-eluting and bare-metal stents: evidence from a comprehensive network meta-analysis," The Lancet, vol. 379, no. 9824, pp. 1393-1402, 2012.

[24] C. Bavishi, U. Baber, S. Panwar et al., "Efficacy and safety of everolimus and zotarolimus-eluting stents versus first-generation drug-eluting stents in patients with diabetes: a meta-analysis of randomized trials," International Journal of Cardiology, vol. 230, pp. 310-318, 2017.

[25] S. E. Capes, D. Hunt, K. Malmberg, and H. C. Gerstein, “Stress hyperglycaemia and increased risk of death after myocardial infarction in patients with and without diabetes: a systematic overview," The Lancet, vol. 355, no. 9206, pp. 773-778, 2000.

[26] C. Berry, S. Noble, J. C. Grégoire et al., "Glycaemic status influences the nature and severity of coronary artery disease," Diabetologia, vol. 53, no. 4, pp. 652-658, 2010.
[27] P. R. Sinnaeve, P. G. Steg, K. A. Fox et al., “Association of elevated fasting glucose with increased short-term and 6-month mortality in ST-segment elevation and non-ST-segment elevation acute coronary syndromes," Archives of Internal Medicine, vol. 169, no. 4, pp. 402-409, 2009.

[28] J. Kowalczyk, M. Mazurek, T. Zielinska et al., "Prognostic significance of $\mathrm{HbAlc}$ in patients with AMI treated invasively and newly detected glucose abnormalities," European Journal of Preventive Cardiology, vol. 22, no. 6, pp. 798-806, 2015.

[29] Y. Liu, J. Li, Z. Zhang, Y. Tang, Z. Chen, and Z. Wang, "Endocrinological analysis of endothelium-dependent vasodilation in middle-aged patients with impaired glucose tolerance during prediabetes mellitus," Experimental and Therapeutic Medicine, vol. 7, no. 3, pp. 697-702, 2014.

[30] E. Elia, F. Montecucco, P. Portincasa, A. Sahebkar, H. Mollazadeh, and F. Carbone, "Update on pathological platelet activation in coronary thrombosis," Journal of Cellular Physiology, vol. 234, no. 3, pp. 2121-2133, 2019.

[31] Q. Zhang, C. Wang, Y. Tang et al., "High glucose up-regulates osteopontin expression by FoxO1 activation in macrophage," Journal of the American College of Cardiology, vol. 234, 2019.

[32] C. Berry, J.-C. Tardif, and M. G. Bourassa, "Coronary heart disease in patients with diabetes," Journal of the American College of Cardiology, vol. 49, no. 6, pp. 643-656, 2007.

[33] T. Christensen and B. Neubauer, "Increased arterial wall stiffness and thickness in medium-sized arteries in patients with insulin-dependent diabetes mellitus," Acta Radiologica, vol. 29, no. 3, pp. 299-302, 1988.

[34] G. Wu, G. Sun, R. Zhao, and M. Sun, "Systematic review/ Meta-analysis Clinical outcomes of second- versus firstgeneration drug-eluting stents in patients with acute myocardial infarction: a meta-analysis of randomized controlled trials," Archives of Medical Science, vol. 4, no. 4, pp. 643-650, 2014.

[35] E. Kedhi, M. E. Gomes, B. Lagerqvist et al., "Clinical impact of second-generation everolimus-eluting stent compared with first-generation drug-eluting stents in diabetes mellitus patients," JACC: Cardiovascular Interventions, vol. 5, no. 11, pp. 1141-1149, 2012.

[36] W.-J. Kim, S.-W. Lee, S.-W. Park et al., "Randomized comparison of everolimus-eluting stent versus sirolimus-eluting stent implantation for de novo coronary artery disease in patients with diabetes mellitus (ESSENCE-DIABETES)," Circulation, vol. 124, no. 8, pp. 886-892, 2011.

[37] U. Kaul, S. Bangalore, A. Seth et al., "Paclitaxel-eluting versus everolimus-eluting coronary stents in diabetes," New England Journal of Medicine, vol. 373, no. 18, pp. 1709-1719, 2015.

[38] M. M. Kok, C. von Birgelen, N. Sattar et al., "Prediabetes and its impact on clinical outcome after coronary intervention in a broad patient population," EuroIntervention, vol. 14, no. 9, pp. e1049-e1056, 2018.

[39] S. Bangalore, S. Kumar, M. Fusaro et al., "Outcomes with various drug eluting or bare metal stents in patients with diabetes mellitus: mixed treatment comparison analysis of 22,844 patient years of follow-up from randomised trials," BMJ, vol. 345, 2012.

[40] E. C. Knudsen, I. Seljeflot, M. Abdelnoor et al., “Abnormal glucose regulation in patients with acute ST- elevation myocardial infarction-a cohort study on 224 patients," Cardiovascular Diabetology, vol. 8, no. 1, 2009. 